\title{
Hiccups Associated with Steroid Injection: A Case Report
}

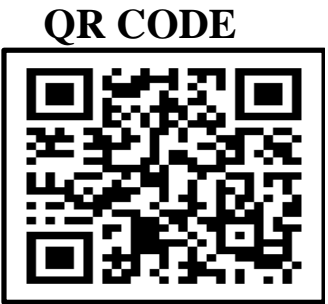

\section{PAYAL RASTOGI ${ }^{1}$, NEYA KAMRA*1, OMMAR MOHAMMAD², TRISHA NAGAR}

Hiccups fall under rare adverse events that occur after an epidural steroid injection. A few studies in medical literature have reported on the physiological and pharmacological aspects of the same and some case reports have also been published. We hereby report a case of a 37-year-old woman who presented with hiccups after epidural steroid injection. She was successful treated with chlorpromazine and omeprazole.

KEYWORDS: Hiccups, Steroid, Adverse Event, Dexamethasone

\section{INTRODUCTION}

Steroid based analgesia is a common procedure in pain units across the world. It is a technique with a low rate of complications, with the most common being vasovagal reactions, increased localized pain and adverse effects of corticosteroids on the central nervous system. ${ }^{1}$ A possible complication of this treatment may be the hiccups, which is classified according to the duration since the onset of the symptoms. It is transient if it lasts less than 48 hours, persistent between 48 hours and one month, and untreatable if it persists more than one month. ${ }^{2}$ This sign has multiple etiologies: toxic-metabolic, central nervous system diseases, or processes that involve involvement of the vagus or phrenic nerve. ${ }^{3}$ The occurrence of persistent hiccups has been described in the literature as an adverse effect following administration of corticosteroids. A few episodes of persistent hiccups due to steroids administered by epidural injection have been described. ${ }^{4-7}$

\section{CASE REPORT}

A 37-year-old female with persistent hiccups since a week presented to our clinic. The hiccups started after an epidural injection of dexamethasone. The relevant medical history included ventricular septal defect, spinal stenosis, diabetes mellitus and two miscarriages. The patient came to us with a clinical picture of hiccups, which caused her to suffer from lack of sleep and severe mental disturbance. The hiccups started few hours after an epidural injection administered to relieve symptoms of spinal stenosis. The presence of constitutional syndrome, toxic habits, changes in her usual medication, recent surgical interventions or symptomatology that may be associated with cardiac, gastrointestinal or central nervous system pathology were ruled out. The patient did not receive any other treatment that could be justified as the causative agent of the hiccups. There were no changes in the chest Xray with regard to previous studies. Laboratory tests were unaltered and inflammatory markers were in the normal ranges. She had previously been treated by her primary care physician with gabapentin and haloperidol, with no relief. At our clinic, symptomatic treatment was done with intravenous chlorpromazine and omeprazole fully remitting the condition 45 minutes after administration. She did not show up again but reported no second occurrence of hiccups over a telephonic conversation.

\section{DISCUSSION}

In the medical literature, persistent hiccups have primarily been associated with oral dexamethasone treatment as an antiemetic at high doses. In this subgroup, the reported incidence is as high as $13 \% .^{8} \mathrm{An}$ incidence of persistent hiccups of $2 \%$ has been reported in the general population following epidural dexamethasone. ${ }^{9}$ There is no publication to capture the incidence of persistent hiccups following administration of other steroids by epidural injection. The occurrence of this adverse effect has been associated with male gender, obesity, young age, use of alkylating agents, elevated body temperature, and elevated hemoglobin, serum creatinine, uric acid or albumin. ${ }^{10}$ The association of local anesthetics with the hiccups is controversial. There is only one report to date that states the use of a local anesthetic, specifically

(C) Payal Rastogi et al. This is an open access article distributed under the terms of the Creative Commons Attribution License CC-BY-NC 4.o, which permits unrestricted use, distribution and reproduction in any medium, provided the use is not commercial and the original author(s) and source are cited. Submitted on: 02-Jul-2021; Accepted on: 13-Sep-2021 
bupivacaine, as a cause of hiccups." In addition, paradoxically, local anesthetics are one of the treatments that have been used successfully for the treatment of refractory persistent hiccups ${ }^{12}$, and therefore with their existing another more likely cause such as the administration of epidural steroid as described in multiple reports of refractory hiccups secondary to corticosteroid therapy ${ }^{5}$, it is reasonable to keep this in mind as an alternative hypothesis. Because of this, the episode has been recorded as an adverse effect of epidurally administered dexamethasone due to the temporal sequence from the puncture, the cessation of the clinical picture after symptomatic treatment without subsequent recurrences, the absence of alternative more likely explanations and the fact that the existing literature supports this etiological diagnosis. ${ }^{4-7,9}$ The hiccup reflex arc is composed of the vagus nerve, the phrenic nerve, and the T6-T12 thoracic sympathetic chain as an afferent pathway and the phrenic nerve as an efferent pathway.

The activation of the reflex arc results in an involuntary inspiration concurrent with the sudden closure of the glottis, resulting in the characteristic sound that gives the hiccups their name.13,14 The pathophysiology of hiccups associated with epidural corticosteroid injection has not yet been established. The competitive binding of steroids to the afferent pathway of the reflex arc has been proposed as an etiological mechanism, which would explain the higher incidence of hiccups at high doses of corticosteroids ${ }^{15}$, as well as a possible decrease of the threshold in action potential by this drug $^{14}$ or by compression of the dural sac by the epidural injection. ${ }^{16}$ In addition, it has been theorized that patients on dexamethasone have a higher incidence of hiccups compared with other steroids due to supposedly better penetration across the bloodbrain barrier. ${ }^{8}$ In fact, in oncological patients, switching from dexamethasone to another corticosteroid such as methylprednisolone or prednisone is recommended as the treatment of choice, since this sign usually disappears without the need to decrease the dose or change the steroid dosage. ${ }^{13}$ There is insufficient evidence to establish clear recommendations on the treatment of persistent hiccups. According to a systematic review ${ }^{17}$, if no specific treatable cause of the condition is identified or the hiccups are refractory to that specific treatment, it is advisable to initiate proton pump inhibitors, especially if symptomatology is consistent with gastroesophageal reflux disease. For vagal maneuvers, although suggested as an initial treatment of hiccups together with proton pump inhibitors, there is no evidence to support their use today. ${ }^{18}$ Baclofen and pregabalin or gabapentin are the symptomatic treatment proposed in the literature as first line in cases with a lack of response to proton pump inhibitors. In the event of refractoriness to these drugs, metoclopramide, and finally chlorpromazine would be used. In the case of the patient described, chlorpromazine was administered. Omeprazole was empirically prescribed for the possibility of gastroesophageal reflux disease, despite the lack of typical symptomatology.

\section{CONCLUSION}

Refractory hiccups are an exceptional adverse effect following administration of dexamethasone by epidural injection. These may result in mental disturbance and impact quality of life. Physicians should consider hiccups as an adverse effect of epidural steroid injection, because it has been repeatedly described in the literature and is potentially underestimated in routine clinical practice.

\section{REFERENCES}

1. El-Yahchouchi CA, Plastaras CT, Maus TP, Carr CM, McCormick ZL, Geske JR, et al. Adverse Event Rates Associated with Transforaminal and Interlaminar Epidural Steroid Injections: A Multi-Institutional Study. Pain Med Malden Mass. 2016;17(2):239-49.

2. Kolodzik PW, Eilers MA. Hiccups (singultus): review and approach to management. Ann Emerg Med. 1991;20(5):565-73.

3. Souadjian JV, Cain JC. Intractable hiccup. Etiologic factors in 220 cases. Postgrad Med. 1968;43(2):72-7.

4. Slipman CW, Shin CH, Patel RK, Braverman DL, Lenrow DA, Ellen MI, et al. Persistent hiccup associated with thoracic epidural injection. Am J Phys Med Rehabil. 2001;8o(8):618-21.

5. Abbasi A, Roque-Dang CM, Malhotra G. Persistent hiccups after interventional pain procedures: a case series and review. PM R 2012;4(2):144-51. https://doi.org/10.1016/j.pmrj.2011.09.005

6. Kaydu A, Kılıç ET, Gökçek E, Akdemir MS. Unexpected Complication after Caudal Epidural Steroid Injection: Hiccup. Anesth Essays Res. 2017;11(3):776-7. https://doi.org/10.4103/aer.AER_90_17 7. Ritz ML, Bailey C, Overstreet K, Gorlin A. Persistent hiccups following cervical epidural steroid injection with betamethasone. Int Med Case Rep J. 2018;11:263-4. 8. Liaw CC, Wang $\mathrm{CH}$, Chang HK, Wang HM, Huang JS, Lin YC, et al. Cisplatin-related hiccups: male predominance, induction by dexamethasone, and 
protection against nausea and vomiting. J Pain Symptom Manage. 2005;30(4):359-66.

9. El Abd O, Amadera J, Pimentel DC, Gomba L. Immediate and acute adverse effects following transforaminal epidural steroid injections with dexamethasone. Pain Physician. 2015;18(3):277-86.

10. Kim J, Oh H, Seo W. Factors associated with dexamethasone-induced hiccups in cancer patients undergoing chemotherapy: A case control study. Eur J Oncol Nurs Off J Eur Oncol Nurs Soc. 2018;37:23-8.

11. McAllister RK, McDavid AJ, Meyer TA, Bittenbinder TM. Recurrent persistent hiccups after epidural steroid injection and analgesia with bupivacaine. Anesth Analg. 2005;100(6):1834-6.

12. Kim JE, Lee MK, Lee DK, Choi SS, Park JS. Continuous cervical epidural block: Treatment for intractable hiccups. Medicine (Baltimore). 2018;97(6):e9444.

https://doi.org/10.1016/j.ejon.2018.10.005

13. Kang JH, Hui D, Kim MJ, Kim HG, Kang MH, Lee G$\mathrm{W}$, et al. Corticosteroid rotation to alleviate dexamethasone-induced hiccup: a case series at a single institution. J Pain Symptom Manage. 2012;43(3):625-30.

14. Davis JN. An experimental study of hiccup. Brain J Neurol. 1970;93(4):851-72.

15. Dickerman RD, Overby C, Eisenberg M, Hollis P, Levine $\mathrm{M}$. The steroid-responsive hiccup reflex arc: competitive binding to the corticosteroid-receptor? Neuro Endocrinol Lett. 2003;24(3-4):167-9.

16. Abubaker AK, Rabadi DK, Kassab M, Al-Qudah MA. Persistent Hiccups After Cervical Epidural Steroid Injection. Am J Case Rep. 2018;19:397-9. https://doi.org/10.12659/ajcr.908536.

17. Steger M, Schneemann M, Fox M. Systemic review: the pathogenesis and pharmacological treatment of hiccups. Aliment Pharmacol Ther. 2015;42(9):1037-50. 18. Polito NB, Fellows SE. Pharmacologic Interventions for Intractable and Persistent Hiccups: A Systematic Review. J Emerg Med. 2017:53(4):540-9. https://doi.org/10.1016/j.jemermed.2017.05.033
Cite this article as:

Rastogi P, Kamra N, Mohammad O, Nagar T. Hiccups Associated with Steroid Injection: A
Case
Report.
Int
Healthc
Res
J.
2021;5(4):CR1-CR3.

https://doi.org/10.26440/IHRJ/0506.09441

AUTHOR AFFILIATIONS: (*Corresponding Author)

1. MD (Dermatology), Consultant Medical Practitioner, Mount Abu, India

2. MD (General Medicine), Consultant Private Practitioner, Kaolack, Senegal

3. MD (General Surgery), Pharmacovigilance Specialist, Baghpat, India

Source of support: Nil, Conflict of interest: None declared

Contact Corresponding Author at: editor[dot]ihrj[at]gmail[dot]com 